\section{Sponsored Visits}

DeAR SIR,

May I, through the pages of the Bulletin, point out a facility which exists to enable psychiatrists to visit underdeveloped countries for short periods of time. Recently I was sponsored by the Inter-University Council on a short-term visit to the Department of Psychiatry in Dar Es Salaam (Tanzania). Travel allowance and reasonable living allowance was provided and I was able to stay for a period of 10 weeks.

When it is realized that there are only five psychiatrists in the whole of Tanzania, for 15 million people, the need is obviously great. The work-load of the hospital was unbelievable, with outpatients running up to 150 to 200 individuals seen in a day. Despite the fact that most of the

\section{Forthcoming Events}

Cruse (National Organization for Widows and their Children) will be holding its seventh annual course of seminars and discussions on counselling before and after bereavement from 10 January to $13 \mathrm{March}$. Information is available from Dr Dora Black, Cruse, Cruse House, 126 Sheen Road, Richmond, Surrey. Telephone: 01-9404818/9047.

A course in forensic medicine leading to the Diploma in Medical Jurieprudence (DMJ) will be held at the London Hospital, Whitechapel, from 3 to 14 March 1980. Course fee £90. Details are available from the Postgraduate Sub-Dean, The London Hospital, Turner Street, London El IBB.

The Wyeth Education Division is sponsoring a symposium on 'Advances in Schizophrenia' which will be held at the Institute of Psychiatry, De Crespigny Park, Denmark Hill, London SE5 on Saturday 22 March 1980. Attendance is limited to psychiatrists in the South East and South West Thames Regions. Further information is available from the Postgraduate Secretary, Wyeth Laboratories, Huntercombe Lane South, Taplow, Maidenhead, Berks.

The International Congress on Death and Dying will be held from 31 March to 2 April 1980 at Imperial College, London SW7. Further details are available from The Conference Office, 37a Maida Vale, London W9.

The 18th Current Themes for Psychistry Conference will be held from 22 to 28 March 1980 at Robens Suite, Guy's Hospital. The conference offers reviews on topics of current interest and accounts of recent research work. Application forms are available from Course Secretary, Mrs June Turner, Keats House, Guy's Hospital, London SE1 9RT. Telephone: 01-407-7600, Ext. 3096. work was done through the aid of a translator (a very eager medical student), I felt that the whole venture was worthwhile, even if I had only been an extra pair of hands.

The Inter-University Council sponsors short-term lecturers up to a period of four months, and this kind of period will fit in ideally between finishing a senior registrar's post and taking up a consultancy. Obviously there are many other under-developed countries as well as Tanzania, but I know that Dr Hauli, the Senior Lecturer and Head of Department, would be only too glad to welcome British psychiatrists for short-term visits.

Brian Harris, Senior Registrar

Department of Psychological Medicine Welsh National School of Medicine, Cardiff
The 10th Imternational Congress of Electroencephalography and Clinical Neurophyalology will be held at the Kyoto International Conference Hall, Japan, from 13 to 18 September, 1981. This Congress will be followed immediately by the Epilepay International Congress 1981 and the 12th World Congress of Neurology, all at the same location. Application for attendance forms should be made before 31 March 1980 to Dr Mitsuru Ebe, Secretary, 10th ICECN, Crescent Plaza 103, 4-6 Minami-Anoyama 2chome. Minato-ku, Tokyo 107, Japan.

The Spring Workshops of The British Association for Behavioural Paychotherapy will be held on 28 and 29 March 1980 at the University of Surrey at Guildford. There will be sessions on assertion therapy, alcohol dependence theory, behaviour therapy, marital therapy and sexual dysfunction. Further details are available from Rod Holland, Senior Clinical Psychologist, NP Department, Royal Naval Hospital, Haslar, Gosport, Hants.

A one-day symposium on Community Psychiatric Nuraing will be held at St George's Hospital, London on 7 February, 1980. Information is available from Professor E. S. Paykel, Department of Psychiatry, St George's Hospital, London SW 17.

A two-year course in Family Therapy for experienced therapists will begin in October 1980. Closing date for applications 21 February. Details: Executive Officer (Training). The Tavistock Centre, 120 Belsize Lane, London NW3 5BA

A Workshop in Psychodrama lead by Marcia Karp, graduate of the Moreno Academy, will be held at Warneford Hospital from 29 February to 2 March. Details: D. S. Bloch, The Warneford Hospital, Oxford OX3 7JX. 